1 Department of Molecular Genetics, The Forsyth Institute, 140 The Fenway, Boston, MA 02115, USA

2 Department of Oral Biology, Harvard Medical School, Boston, MA 02115, USA

3 Department of Oral Microbiology, Guy's, King's and St Thomas' Dental Institute, King's College London, Guy's Hospital, London SE1 9RT, UK

\section{Characterization of novel human oral isolates and cloned 165 rDNA sequences that fall in the family Coriobacteriaceae: description of Olsenella gen. nov., reclassification of Lactobacillus uli as Olsenella uli comb. nov. and description of Olsenella profusa sp. nov.}

\author{
Floyd E. Dewhirst, ${ }^{1,2}$ Bruce J. Paster, ${ }^{1,2}$ Nia Tzellas, ${ }^{1}$ Brittney Coleman, ${ }^{1}$ \\ Julia Downes, ${ }^{3}$ David A. Spratt ${ }^{3}$ and William G. Wade ${ }^{3}$ \\ Author for correspondence: Floyd E. Dewhirst. Tel: +1 6172625200 ext. 298. Fax: +1 6172479683.
e-mail: fdewhirst@forsyth.org
}

The diversity of organisms present in the subgingival pockets of patients with periodontitis and acute necrotizing ulcerative gingivitis (ANUG) were examined previously. The 16S rRNA genes of subgingival plaque bacteria were amplified using PCR with a universal forward primer and a spirochaeteselective reverse primer. The amplified DNA was cloned into Escherichia coli. In one subject with ANUG, 70 clones were sequenced. Seventy-five per cent of the clones were spirochaetal, as expected. Twelve of the remaining clones fell into two clusters that represent novel phylotypes in the family Coriobacteriaceae. The first novel phylotype was most closely related to Atopobium rimae $\mathbf{( 9 8 \%}$ similarity). The phylotype probably represents a novel Atopobium species, but will not be named until cultivable strains are obtained. The second novel phylotype was only $91 \%$ similar to described Atopobium species and $84 \%$ similar to Coriobacterium glomerans. The 16S rRNA sequences of the type strain of Lactobacillus uli and a strain representing the Moores' Eubacterium group D52 were determined as part of on ongoing sequence analysis of oral bacteria. The sequence for $L$. uli was more than $99.8 \%$ similar to sequences for the second clone phylotype. It therefore appears that the second clone phylotype and $L$. uli represent the same species. The sequence for the Eubacterium D52 strain was $95.6 \%$ similar to that of $L$. uli. The $G+C$ content of the DNA of $L$. uli and Eubacterium D52 is 63-64 mol\%. These organisms are thus distinct from the neighbouring genus Atopobium, which has a DNA G+C content of 35-46 mol\%. A new genus, Olsenella gen. nov., is proposed for these two species on the basis of phenotypic characteristics and 16S rRNA sequence analysis to include Olsenella uli comb. nov. and Olsenella profusa sp. nov.

Keywords: Atopobium, Coriobacteriaceae, Olsenella, rRNA, phylogeny

\section{INTRODUCTION}

This study is part of our ongoing efforts to determine

Abbreviations: FAA, fastidious anaerobe agar; PYG, peptone/yeast extract/glucose.

The GenBank accession numbers for the 165 rDNA sequences determined in this study are AF287760 and AF292371-AF292375. the 16S rRNA sequences of essentially all of the 500-600 cultivable and uncultivable species found in the human oral cavity. In a previous study, we examined the diversity of cultivable and uncultivable oral spirochaetes in patients with severe periodontal disease by cloning and sequencing $16 \mathrm{~S}$ rRNA genes that were amplified by PCR from DNA extracted from subgingival plaque samples (Dewhirst et al., 2000). 
Using a 16S rRNA universal forward primer and a spirochaete-selective reverse primer, approximately $75 \%$ of the clones obtained were found to represent Treponema species, on the basis of sequence analysis. The majority of the non-spirochaete clones were closely related to the genus Atopobium in the family Coriobacteriaceae. The purpose of this study was to clarify the taxonomy and phylogeny of human oral microbes in the family Coriobacteriaceae.

The genus Atopobium was created by Collins \& Wallbanks (1992) for the phylogenetically misplaced species Lactobacillus minutus, Lactobacillus rimae and Streptococcus parvulus. 16S rRNA sequence analysis demonstrated that Atopobium minutum, Atopobium rimae and Atopobium parvulum were closely related to one another, and they were considered a distinct line of descent within the lactic acid bacteria. While the $\mathrm{G}+\mathrm{C}$ content of these species ranged from 35 to $46 \mathrm{~mol} \%$, suggesting that the genus is part of the low- $\mathrm{G}+\mathrm{C}$ Gram-positive bacteria, they actually represent a deep branch within the high-G+C Gram-positive bacteria, the Actinobacteria (Stackebrandt et al., 1997; Stackebrandt \& Ludwig, 1994). The family Coriobacteriaceae contains several genera: Atopobium (Collins \& Wallbanks, 1992), Coriobacterium (Haas \& König, 1988), Collinsella (Kageyama et al., 1999a), Cryptobacterium (Nakazawa et al., 1999), Slackia, Eggerthella (Wade et al., 1999) and Denitrobacterium (Anderson et al., 2000). As part of our analysis of cultivable human oral bacteria, we have found that the type strain of Lactobacillus uli falls into the family Coriobacteriaceae on the basis of $16 \mathrm{~S}$ rRNA sequence analysis.

In the course of their careers at the Virginia Polytechnic Institute (VPI), W.E.C. Moore and L.V.H. Moore established a large collection of gut and oral bacteria. They placed their isolates into hundreds of groups on the basis of a large range of phenotypic tests including fatty acid methyl ester (FAME) analysis (Holdeman et al., 1977). Many of the groups were named formally before they retired. However, strains representing over 200 unnamed taxa remain in the collection, which was distributed to a few colleagues. One of these groups, Eubacterium D52, was also found to fall within the Coriobacteriaceae and was therefore included in this study.

\section{METHODS}

Sample collection. Plaque samples were obtained from a patient with acute necrotizing ulcerative gingivitis (ANUG). After removal of supragingival plaque using a sterile Gracey curette, subgingival plaque samples were removed from four lower anterior sites using individual sterile Gracey curettes and suspended directly in $100 \mu \mathrm{l}$ of $250 \mathrm{mM}$ Tris/HCl, pH 7. The four samples were examined immediately by phase microscopy to identify the sites with the highest proportion and diversity of spirochaetes.

Bacterial strains. L. uli ATCC $49627^{\mathrm{T}}$ was obtained from the ATCC. Eubacterium D52 strains D315A-29 and D288A-6, originally isolated from subgingival plaque of subjects with adult periodontitis and characterized by W.E.C. and L.V.H. Moore, were obtained from Anne Tanner (Forsyth Institute). Bacteria were maintained on fastidious anaerobe agar (FAA; LabM) supplemented with 5\% horse blood incubated under anaerobic conditions.

Biochemical tests. Fermentation tests were performed using pre-reduced, anaerobically sterilized sugars according to the methods of Holdeman et al. (1977) except that the prereduced, anaerobically sterilized media were prepared in an anaerobic workstation using pre-reduced distilled water. Other biochemical tests were performed as described by Holdeman et al. (1977) and Summanen et al. (1993).

Metabolic end-product analysis. Bacterial strains were grown in peptone/yeast extract/glucose (PYG) broth and shortchain volatile and non-volatile fatty acids were extracted by standard methods (Holdeman et al., 1977). Analysis was performed by GC with a capillary column coated with $\mathrm{CP}$ Wax 58 solid phase.

Enzyme profiles. Enzyme profiles were generated with the Rapid ID32A anaerobe identification kit (bioMérieux) according to the manufacturer's instructions. Bacteria were harvested from blood agar plates [blood agar base no. 2 (LabM) plus $5 \%$ horse blood] incubated anaerobically at $37^{\circ} \mathrm{C}$ for $72 \mathrm{~h}$.

DNA isolation and PCR amplification. DNA was released from the plaque samples by adding $5 \mu$ plaque suspension to $15 \mu \mathrm{l}$ Gene Releaser (BioVentures) and following the manufacturer's microwave protocol. PCR was performed in thinwalled tubes with a Perkin-Elmer 480 thermal cycler, GeneAmp PCR reagent kit and AmpliWax PCR Gem 100s. Forward primer C75 (Escherichia coli positions 7-27; 5'GAGAGTTTGATYCTGGCTCAG-3') and reverse primer C90 (1501-1483; 5'-GTTACGACTTCACCCTCCT-3') were used. The $20 \mu \mathrm{l}$ from the Gene Releaser step was combined with $1 \mu \mathrm{M}$ primers and other reagents in the Hot Start protocol suggested by Perkin-Elmer. The following conditions were used for amplification: denaturation at $72{ }^{\circ} \mathrm{C}$ for $45 \mathrm{~s}$, annealing at $60^{\circ} \mathrm{C}$ for $45 \mathrm{~s}$ and elongation at $72{ }^{\circ} \mathrm{C}$ for $45 \mathrm{~s}$, with $5 \mathrm{~s}$ added for each elongation step. Thirty cycles were performed, followed by a final elongation step at $72{ }^{\circ} \mathrm{C}$ for $15 \mathrm{~min}$. The purity of the product was determined by electrophoresis in a $1 \%$ agarose gel. DNA was stained with ethidium bromide and viewed under longwavelength UV light.

Cloning. Cloning of PCR-amplified DNA was performed using either a TA cloning kit (Invitrogen) or Prime PCR Cloner cloning system (5 Prime-3 Prime) following the manufacturers' instructions.

Library screening. Up to 100 white clones were picked for each reaction. The sizes of inserts were determined by PCR using flanking vector primers followed by electrophoresis on a $1.5 \%$ agarose gel.

Purification of PCR products. The amplified DNA was purified by precipitation with PEG 8000 (Kusukawa et al., 1990). After removal of Ampliwax, 0.6 vols 20\% PEG 8000 (Sigma) in $2.5 \mathrm{M} \mathrm{NaCl}$ was added and the mixture was incubated at $37^{\circ} \mathrm{C}$ for $10 \mathrm{~min}$. The sample was centrifuged for $15 \mathrm{~min}$ at $15000 \mathrm{~g}$ and the pellet was washed with $80 \%$ ethanol and pelleted as before. The pellet was air-dried and dissolved in $30 \mu \mathrm{l}$ distilled water and used for cycle sequencing as described below. 
Table 1. Strains included in analysis of the family Coriobacteriaceae

\begin{tabular}{|c|c|c|c|}
\hline Species & Collection no. & $\begin{array}{c}\text { 16S rDNA } \\
\text { GenBank accession no. }\end{array}$ & Reference \\
\hline Atopobium fossor & ATCC $43386^{\mathrm{T}}$ & L34620 & Kageyama et al. (1999b) \\
\hline Atopobium minutum & ATCC $33267^{\mathrm{T}}$ & X67148 & Collins \& Wallbanks (1992) \\
\hline Atopobium parvulum & ATCC $33793^{\mathrm{T}}$ & AF292372 & This paper \\
\hline Atopobium rimae & ATCC $49626^{\mathrm{T}}$ & AF292371 & This paper \\
\hline Atopobium sp. ANUG-C19 & Clone & AF 287760 & This paper \\
\hline Atopobium vaginae & CCUG $38953^{\mathrm{T}}$ & Y17195 & Rodriguez Jovita et al. (1999) \\
\hline Collinsella aerofaciens & JCM $10188^{\mathrm{T}}$ & AB011816 & Kageyama et al. (1999a) \\
\hline Collinsella aerofaciens & JCM 7791 & $\mathrm{AB} 011815$ & Kageyama et al. (1999a) \\
\hline Coriobacterium glomerans & ATCC $49209^{\mathrm{T}}$ & X79048 & Haas \& König (1988) \\
\hline Cryptobacterium curtum & ATCC $700683^{\mathrm{T}}$ & AB019260 & Nakazawa et al. (1999) \\
\hline Denitrobacterium detoxificans & ATCC $700546^{\mathrm{T}}$ & U43492 & Anderson et al. (2000) \\
\hline Eggerthella lenta & ATCC $25559^{\mathrm{T}}$ & AF292375 & This paper \\
\hline Olsenella uli & ATCC $49627^{\mathrm{T}}$ & AF292373 & This paper \\
\hline Olsenella uli ANUG-D15 & Clone & Similar to above & This paper \\
\hline Olsenella profusa D315A-29 & DSM $13989^{\mathrm{T}}$ & AF292374 & This paper \\
\hline Olsenella profusa D288A-6 & None & Similar to above & This paper \\
\hline Olsenella sp. & Clone, cow rumen & AB034002 & GenBank, unpublished \\
\hline Olsenella sp. & Clone, cow rumen & AB034096 & GenBank, unpublished \\
\hline 'Olsenella oviles' A2 & None & AJ 251324 & GenBank, unpublished \\
\hline Slackia exigua & ATCC $700122^{\mathrm{T}}$ & AF 101240 & Wade et al. (1999) \\
\hline Slackia heliotrinireducens & NCTC $11029^{\mathrm{T}}$ & AF101241 & Wade et al. (1999) \\
\hline
\end{tabular}

Sequencing methods. The DNA sample from PCR was sequenced directly using a cycle-sequencing kit ( fmol DNA Sequencing System; Promega). The manufacturer's protocol was followed. The eight sequencing primers used have been reported previously (Mendes et al., 1996). Primers were endlabelled with ${ }^{33} \mathrm{P}$ (NEN/Dupont) using the manufacturer's protocol. Approximately $100 \mathrm{ng}$ purified DNA from the PCR was used for sequencing. Reaction products were loaded onto $8 \%$ polyacrylamide/urea gels, electrophoresed and detected by exposure to X-ray film for $24 \mathrm{~h}$.

16S rRNA data analysis. A program set for data entry, editing, sequence alignment, secondary structure comparison, similarity matrix generation and dendrogram construction for 16S rRNA data was written in Microsoft Quick BASIC for use on PC-compatible computers (Paster \& Dewhirst, 1988). RNA sequences were entered and aligned as described previously (Paster \& Dewhirst, 1988). Our sequence database contains approximately 1000 sequences determined in our laboratory and another 500 obtained from GenBank or the Ribosomal Database Project (Maidak et al., 2000). Strains used in the $16 \mathrm{~S}$ rRNA analysis are given in Table 1. Similarity matrices were constructed from the aligned sequences by using only those sequence positions for which $90 \%$ of the strains had data. The similarity matrices were corrected for multiple base changes at single positions by the method of Jukes \& Cantor (1969). Phylogenetic trees were constructed using the neighbour-joining method of Saitou \& Nei (1987). PHYLIP version 3.5 was used for maximum-likelihood analysis (Felsenstein, 1993).

Estimation of $\mathbf{G}+\mathbf{C}$ content of DNA. The $\mathrm{G}+\mathrm{C}$ content of DNA was estimated by an HPLC method, as described previously (Wade et al., 1999).

Nucleic acid sequence accession numbers. The sequences for each of the strains examined in this report have been deposited in GenBank under the accession numbers listed in Table 1.

\section{RESULTS AND DISCUSSION}

Essentially complete $16 \mathrm{~S}$ rRNA sequences were determined for those species listed in Table 1. Corrections and additions were made to the sequences of the type strains of $A$. rimae and $A$. parvulum and were deposited in GenBank (see Table 1). A phylogenetic tree generated by the neighbour-joining method is presented in Fig. 1. When the species with short sequences, Atopobium vaginae, Spherobacter thermophilus, Bifidobacterium longum and Bifidobacterium infantis, were excluded, trees of the same topology were obtained using both the neighbour-joining and maximum-likelihood methods. Examination of the target sequence for the spirochaete-selective reverse 16S rRNA primer shows that the clones, as well as all members of the family Coriobacteriaceae, have a sequence identical to spirochaetes at the primer site and should therefore amplify with primer $\mathrm{C} 90$.

\section{Analysis of clones}

The clone sequences fell into two tight clusters. Representative of the first group is clone ANUG-C19, which had $98 \%$ sequence similarity to the type strain of $A$. rimae. This sequence difference is at a level that probably indicates a novel species. However, since we currently have no cultivable strains representing this group, we will not formally name it, but rather give it 


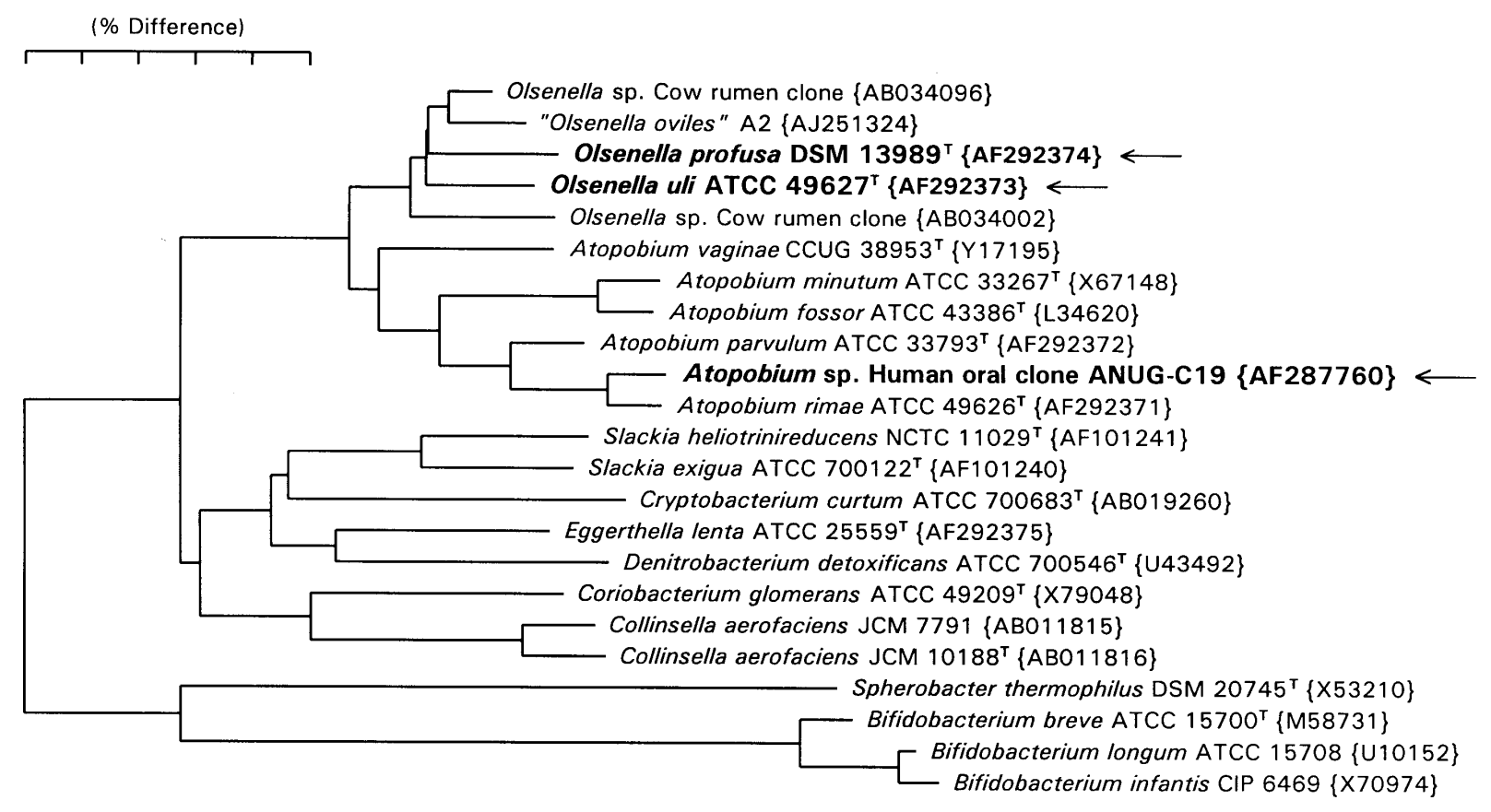

Fig. 1. $16 \mathrm{~S}$ rDNA-based phylogenetic tree for the family Coriobacteriaceae. Bar, $5 \%$ difference in nucleotide sequences as estimated using the correction of Jukes \& Cantor (1969). Distances are determined by measuring the lengths of the horizontal lines connecting two sequences. Sequence accession numbers are given in brackets.

the informal designation Atopobium sp. clone ANUGC19.

The second clone group, represented by clone ANUGD15, had more than $99.8 \%$ sequence similarity to the type strain of $L$. uli. The three-base difference is within species variation for $16 \mathrm{~S}$ rRNA sequences. The $\mathrm{G}+\mathrm{C}$ content of the DNA of $L$. uli was redetermined in this study and is $63-64 \mathrm{~mol} \%$. This is substantially above the $53 \mathrm{~mol} \%$ reported previously (Olsen et al., 1991). The higher $\mathrm{G}+\mathrm{C}$ content clearly places $L$. uli outside the genus Atopobium, species of which have $\mathrm{G}+\mathrm{C}$ contents ranging from 35 to $46 \mathrm{~mol} \%$. In order to accommodate this species, we propose the genus Olsenella gen. nov. and rename L. uli as Olsenella uli comb. nov. The type species of the two genera, $A$. minutum and $O$. uli, share only $91 \%$ 16S rDNA sequence similarity (Fig. 1).

Spirochaete libraries from three other patients have subsequently been analysed and they contained clones identified as $A$. rimae (96 clones) and A. parvulum ( 3 clones). We have not detected additional clones for group ANUG-C19.

\section{VPI Eubacterium D52}

The genus Eubacterium was long a taxonomic dumping ground for Gram-positive, obligately anaerobic, chemo-organotrophic rods that produce large amounts of butyric, acetic or formic acids or no major fatty acids and that don't fit into other genera. The VPI Eubacterium D52 group was established on the basis of isolates having the general phenotypic characteristics of the genus Eubacterium, and isolates were then subdivided into groups on the basis of FAME analysis (Moore et al., 1994). Many species placed in the genus, such as Eubacterium exiguum, have been removed and placed in other genera (in this case, as Slackia exigua; Wade et al., 1999). Full sequencing of 16S rDNA from strain D315A-29 indicated that it is unrelated to Eubacterium limosum, but rather $96 \%$ similar to O. uli (Fig. 1). Strain D288A-6 had a sequence identical to that of strain D315A-29 over 500 bases at the $5^{\prime}$ end of the gene. Phenotypic analysis confirmed that group D52 strains represent a novel species related to O. uli. We propose the name Olsenella profusa sp. nov. for VPI Eubacterium group D52. The phenotypic traits that differentiate $O$. uli from $O$. profusa are given in Table 2 .

\section{GenBank sequences of organisms related to the genus Olsenella}

A search of GenBank using the $O$. uli sequence revealed three sequences from rumen clones or isolates that may represent additional species in the genus Olsenella: AB034002, AB034096 and AJ251324. The first two sequences are from rumen clones and the last sequence is from a rumen isolate that has been given the informal name 'Atopobium oviles'. The sequence from 'Atopobium oviles' has $97 \cdot 3 \%$ mean similarity to those of $O$. uli and $O$. profusa, but only $93.5 \%$ mean similarity to sequences of Atopobium species. The informal name of this organism should be changed to 
Table 2. Differential characteristics of Olsenella uli and Olsenella profusa

Data for $O$. uli were taken from Olsen et al. (1991). Colony morphology was determined after $7 \mathrm{~d}$ on FAA. d, 5-30\% strains positive.

\begin{tabular}{|lcc|}
\hline Test & O. uli (48 strains) & O. profusa (2 strains) \\
\hline Rapid ID 32A profile & 2012033705 & 4516053705 \\
Growth in PYG broth & Poor (1+) & Good (3-4+) \\
Stimulation of growth by Tween 80 & Marked & Slight \\
Arginine hydrolysis & + & - \\
Fermentation of: & - & + \\
Arabinose & $\mathrm{d}$ & + \\
Cellobiose & $\mathrm{d}$ & + \\
Lactose & - & + \\
Mannitol & - & + \\
Melibiose & - & + \\
Raffinose & Raised, grey, semi-translucent & Pyramidal, cream, opaque \\
Colony morphology & & \\
\hline
\end{tabular}

Table 3. Differentiation of genera in the family Coriobacteriaceae

\begin{tabular}{|c|c|c|c|c|c|c|c|c|}
\hline Character & Olsenella & Atopobium & Slackia & Cryptobacterium & Eggerthella & Denitrobacterium & Coriobacterium & Collinsella \\
\hline Glucose fermentation & + & + & - & - & - & - & + & + \\
\hline Metabolic end-products* & $\mathrm{a}, \mathrm{L},(\mathrm{s})$ & $\mathrm{a}, \mathrm{L},(\mathrm{s})$ & (a) & None & $(\mathrm{a}, 1, \mathrm{~s})$ & ND & $\mathrm{a}, 1$ & $\mathrm{a}, 1$ \\
\hline \multicolumn{9}{|l|}{ Growth stimulated by: } \\
\hline Tween 80 & + & + & - & - & - & ND & ND & + \\
\hline Arginine & - & - & + & + & + & ND & ND & ND \\
\hline Growth in $20 \%$ bile & $\mathrm{v}$ & - & - & - & + & ND & ND & ND \\
\hline Nitrate reduction & - & - & $\mathrm{v}$ & - & + & $\mathrm{v}$ & ND & - \\
\hline Hydrogen production & $\mathrm{v}$ & - & ND & ND & - & + & + & + \\
\hline Cell wall peptidoglycan type & ND & $\mathrm{A} 3 \gamma, \mathrm{A} 4 \alpha, \mathrm{A} 4 \beta \mathrm{p}$ & ND & $\mathrm{ND}$ & $\mathrm{A} 3 \gamma$ & ND & $\mathrm{A} 4 \alpha$ & $\mathrm{A} 4 \beta$ \\
\hline Major cellular fatty acids & $\mathrm{C} 18: 1$ cis $9 \dagger$ & $\mathrm{C} 18: 1$ cis 9 & $\mathrm{C} 18: 1$ & ND & $\mathrm{C} 14: 0 \mathrm{br}, \mathrm{C} 15: 0 \mathrm{br}$ & $\mathrm{C} 14: 0 \mathrm{br}, \mathrm{C} 15: 0 \mathrm{br}$ & ND & ND \\
\hline DNA $\mathrm{G}+\mathrm{C}$ content $(\mathrm{mol} \%)$ & $63-64$ & $35-46$ & $60-64$ & $50-51$ & 62 & $56-60$ & $60-61$ & $60-61$ \\
\hline Source & Human oral cavity & Mammals & $\begin{array}{l}\text { Human oral } \\
\text { cavity }\end{array}$ & $\begin{array}{l}\text { Human oral } \\
\text { cavity }\end{array}$ & Human intestine & Bovine rumen & $\begin{array}{l}\text { Red soldier beetle } \\
\text { intestine }\end{array}$ & $\begin{array}{l}\text { Human } \\
\text { intestine }\end{array}$ \\
\hline
\end{tabular}

* a, Acetic acid; 1 , lactic acid; $\mathrm{s}$, succinic acid. Capital letters indicate major products. Products in parentheses indicate strain variation. $\dagger$ Determined for $O$. uli but not for $O$. profusa.

ND, Not determined; v, variable; br, branched.

'Olsenella oviles'. The phylogenetic positions of these sequences are shown in Fig. 1. The taxonomy of the rumen organisms will require the isolation of additional strains and further study before formal naming is appropriate.

\section{Differentiation of genera in the family Coriobacteriaceae}

In recent years, five genera have been added to the family Coriobacteriaceae (Anderson et al., 2000; Kageyama et al., 1999a; Nakazawa et al., 1999; Wade et al., 1999). Unfortunately, because these organisms came from diverse habitats, widely differing methods were used for phenotypic characterization. As shown in Table 3, almost no phenotypic characters have been determined for all genera. As investigators extend research on each of these genera, it is hoped that all of the phenotypic tests listed in Table 3 can be determined. The menaquinone content of species in the
Coriobacteriaceae should be examined to determine whether the unique dimethylmenaquinone present in Eggerthella lenta is also present in other genera (Collins et al., 1985). This is a very distinct and potentially valuable chemotaxonomic marker. Olsenella can be differentiated from Atopobium by $\mathrm{G}+\mathrm{C}$ content of the DNA and from Collinsella by site of origin. Olsenella can be differentiated from Slackia and Eggerthella by being fermentative and from Cryptobacterium by the production of acetic and lactic acids and the stimulation of growth by Tween 80 rather than by arginine. The remaining genera, Denitrobacterium and Coriobacterium, have not been recovered from humans.

\section{S rRNA base signatures}

In their proposal for a new hierarchic classification of the Actinobacteria, Stackebrandt and co-workers identified signature nucleotides for each taxa. The subclass, order and family were characterized by 
Table 4. 16S rRNA base signatures

Taxa are identified as: 1, Olsenella; 2, Atopobium; 3, Collinsella; 4, Coriobacterium; 5, Denitrobacterium; 6, Eggerthella; 7 , Cryptobacterium; 8, Slackia; 9, Coriobacteriaceae. Base signatures in bold are present in at least $95 \%$ of the Coriobacteriaceae and fewer than $15 \%$ of other bacteria. When two bases are listed, the bases pair with one another in a helix. Base positions are numbered relative to E. coli. The number of species with signature/total number of species in taxon is given. Two strains of Collinsella aerofaciens were included, as they differ significantly.

\begin{tabular}{|c|c|c|c|c|c|c|c|c|c|c|c|c|}
\hline No. & Base(s) & Position(s) & 1 & 2 & 3 & 4 & 5 & 6 & 7 & 8 & 9 & Bacteria \\
\hline 1 & $\mathrm{C}-\mathrm{G}$ & $113-314$ & $5 / 5$ & $6 / 6$ & $2 / 2$ & $1 / 1$ & $0 / 1$ & $0 / 1$ & $0 / 1$ & $0 / 2$ & $14 / 19$ & $<5 \%$ \\
\hline 2 & G-C & 294-303 & $5 / 5$ & $6 / 6$ & $2 / 2$ & $1 / 1$ & $0 / 1$ & $1 / 1$ & $1 / 1$ & $2 / 2$ & $18 / 19$ & None \\
\hline 3 & $\mathrm{U}-\mathrm{A}$ & 295-302 & $5 / 5$ & $6 / 6$ & $2 / 2$ & $1 / 1$ & $0 / 1$ & $1 / 1$ & $1 / 1$ & $0 / 2$ & $16 / 19$ & $<5 \%$ \\
\hline 4 & $\mathbf{C}-\mathbf{G}$ & $407-435 *$ & $5 / 5$ & $6 / 6$ & $2 / 2$ & $1 / 1$ & $1 / 1$ & $1 / 1$ & $1 / 1$ & $2 / 2$ & $19 / 19$ & $<15 \%$ \\
\hline 5 & G-C & $613-627 *$ & $5 / 5$ & $6 / 6$ & $2 / 2$ & $1 / 1$ & $1 / 1$ & $1 / 1$ & $1 / 1$ & $2 / 2$ & $19 / 19$ & $<5 \%$ \\
\hline 6 & $\mathrm{G}-\mathrm{C}$ & $670-736$ & $5 / 5$ & $6 / 6$ & $2 / 2$ & $1 / 1$ & $1 / 1$ & $1 / 1$ & $1 / 1$ & $2 / 2$ & $19 / 19$ & $>50 \%$ \\
\hline 7 & $\mathbf{U}-\mathbf{A}$ & 771-808 & $5 / 5$ & $6 / 6$ & $2 / 2$ & $1 / 1$ & $0 / 1$ & $1 / 1$ & $1 / 1$ & $2 / 2$ & $18 / 19$ & $<15 \%$ \\
\hline 8 & $\mathrm{~A}-\mathrm{U}$ & $772-807$ & $5 / 5$ & $6 / 6$ & $0 / 2$ & $0 / 1$ & $0 / 1$ & $1 / 1$ & $0 / 1$ & $0 / 2$ & $12 / 19$ & $<15 \%$ \\
\hline 9 & $\mathrm{~A}-\mathrm{U}$ & $823-877$ & $5 / 5$ & $6 / 6$ & $2 / 2$ & $1 / 1$ & $0 / 1$ & $1 / 1$ & $0 / 1$ & $0 / 2$ & $15 / 19$ & $>50 \%$ \\
\hline 10 & $\mathbf{A}-\mathbf{U}$ & 941-1342 & $5 / 5$ & $6 / 6$ & $2 / 2$ & $1 / 1$ & $1 / 1$ & $1 / 1$ & $1 / 1$ & $2 / 2$ & $19 / 19$ & $<5 \% \dagger$ \\
\hline 11 & $\mathrm{U}-\mathrm{G}$ & $950-1231$ & $5 / 5$ & $6 / 6$ & $2 / 2$ & $1 / 1$ & $1 / 1$ & $1 / 1$ & $1 / 1$ & $2 / 2$ & $19 / 19$ & $>90 \%$ \\
\hline 12 & $\mathrm{G}-\mathrm{C}$ & $1120-1153$ & $5 / 5$ & $6 / 6$ & $2 / 2$ & $1 / 1$ & $0 / 1$ & $0 / 1$ & $1 / 1$ & $2 / 2$ & $17 / 19$ & $<30 \%$ \\
\hline 13 & $\mathrm{C}$ & 1148 & $5 / 5$ & $6 / 6$ & $2 / 2$ & $1 / 1$ & $0 / 1$ & $0 / 1$ & $0 / 1$ & $0 / 2$ & $14 / 19$ & None \\
\hline 14 & $\mathrm{C}-\mathrm{G}$ & $1165-1171$ & $5 / 5$ & $6 / 6$ & $2 / 2$ & $1 / 1$ & $1 / 1$ & $1 / 1$ & $1 / 1$ & $2 / 2$ & $19 / 19$ & $<30 \%$ \\
\hline 15 & $\mathrm{G}-\mathrm{C}$ & $1242-1295$ & $4 / 5$ & $4 / 6$ & $2 / 2$ & $1 / 1$ & $1 / 1$ & $1 / 1$ & $0 / 1$ & $2 / 2$ & $15 / 19$ & $<5 \%$ \\
\hline 16 & $\mathrm{G}-\mathrm{C}$ & $1313-1324$ & $5 / 5$ & $6 / 6$ & $2 / 2$ & $1 / 1$ & $1 / 1$ & $1 / 1$ & $1 / 1$ & $2 / 2$ & $19 / 19$ & $<30 \%$ \\
\hline 17 & $\mathbf{C}$ & $1321 *$ & $5 / 5$ & $5 / 6$ & $2 / 2$ & $1 / 1$ & $1 / 1$ & $1 / 1$ & $1 / 1$ & $2 / 2$ & $18 / 19$ & $<5 \%$ \\
\hline 18 & $\mathrm{~A}-\mathrm{U}$ & $1410-1490$ & $5 / 5$ & $6 / 6$ & $2 / 2$ & $1 / 1$ & $1 / 1$ & $1 / 1$ & $1 / 1$ & $2 / 2$ & $19 / 19$ & $>50 \%$ \\
\hline 19 & $\mathbf{C}-\mathbf{G}$ & $1415-1485 *$ & $5 / 5$ & $6 / 6$ & $2 / 2$ & $1 / 1$ & $1 / 1$ & $1 / 1$ & $1 / 1$ & $2 / 2$ & $19 / 19$ & Spirochaetes \\
\hline 20 & $\mathbf{C}-\mathbf{G}$ & 1416-1484* & $5 / 5$ & $6 / 6$ & $2 / 2$ & $1 / 1$ & $1 / 1$ & $1 / 1$ & $1 / 1$ & $2 / 2$ & $19 / 19$ & Spirochaetes \\
\hline
\end{tabular}

* Signatures not included by Stackebrandt et al. (1997).

$\dagger$ Clostridia, $50 \%$.

$\$ \mathrm{G}$ at position 1242 is present in essentially all bacteria. The $\mathrm{C}$ present in most members of the Coriobacteriaceae at position 1295 is rare in other bacteria, which have a U.

possession of 15 base signatures (Stackebrandt et al., 1997). Their analysis was based on sequence information for three Atopobium species and one Coriobacterium species. The base signatures have been reexamined on the basis of full sequences for 20 strains falling in the eight genera of the Coriobacteriaceae (Table 4). Seven of the previously identified signatures do not apply to $93 \%$ of species (signatures $1,3,8,9,12$, 13, 15 in Table 4). The previously identified signatures were chosen on the basis of aligned Actinobacteria sequences. Our examination of the aligned sequences identified five additional base signatures for the family Coriobacteriaceae. Our signature analysis was performed using 60 representatives of all of the major phyla of bacteria. The previously selected signatures varied widely in their presence in Bacteria. Several signatures should be discarded as common to most bacteria. The signatures in bold in Table 4 are present in at least $93 \%$ of members of the Coriobacteriaceae and in fewer than $15 \%$ of other bacteria. The bases GG at positions 1484 and 1485 are common in the Archaea, but are not found in the Bacteria except in the spirochaetes, the Thermotogales, the order Haloanaerobiales and the family Coriobacteriaceae. These bases were present in the PCR primer used in our cloning experiments.

\section{Description of Olsenella gen. nov.}

Olsenella (Ol.sen.el'1a. L. fem. dim. ending -ella, N.L. fem. n. Olsenella of Olsen, named to honour Ingar Olsen, a contemporary Norwegian microbiologist, who first described Lactobacillus uli).

Cells are small, elliptical, Gram-positive, non-motile rods that occur singly, in pairs and in short chains. Spores are not formed. Cells are strictly anaerobic. Fermentation products from glucose are lactic and acetic acids. Cells do not produce catalase, urease or indole or reduce nitrate. The major fatty acid of the cell membrane is $\mathrm{C} 18: 1$ cis 9 . The $\mathrm{G}+\mathrm{C}$ content of the DNA is $63-64 \mathrm{~mol} \%$. Found in the human oral cavity and likely in bovine rumen. The type species is Olsenella uli.

\section{Description of Olsenella uli comb. nov.}

Olsenella uli (u'li. Gr. n. oulon the gum; N.L. gen. n. uli of the gum). 
Basonym: Lactobacillus uli Olsen et al. 1991.

Characteristics of the species are as described previously by Olsen et al. (1991) with the following additions and corrections. The $\mathrm{G}+\mathrm{C}$ content of the DNA for the type strain is $64 \mathrm{~mol} \%$. The Rapid ID32A profile is 2012033705 . The GenBank accession number for the 16S rRNA sequence is AF292373. The type strain is strain VPI D76D-27C ${ }^{\mathrm{T}}$ (=ATCC $\left.49627^{\mathrm{T}}\right)$.

\section{Description of Olsenella profusa sp. nov.}

Olsenella profusa (pro.fus'a. L. adj. profusus profuse, referring to the good growth of the organism).

Previously designated Eubacterium group D52 by W.E.C. and L.V.H. Moore. The description is based on two strains isolated from the oral cavity. Cells are obligately anaerobic, non-spore-forming, non-motile, Gram-positive, short rods, $0.6 \times 0.8-2.0 \mu \mathrm{m}$. Cells occur singly or in chains. After $7 \mathrm{~d}$ of incubation on FAA plates, colonies are approximately $1-1.3 \mathrm{~mm}$ in diameter, circular, entire, pulvinate to pyramidal, cream coloured and opaque when viewed under a plate microscope. Growth in broth media is good and is stimulated only slightly by addition of Tween 80 . Arabinose, cellobiose, fructose, glucose, lactose, maltose, mannitol, mannose, melibiose, raffinose, salicin, sucrose and trehalose are fermented. Melezitose and rhamnose are not fermented. Aesculin is hydrolysed but arginine and starch are not. Gelatin is not liquefied and meat is not digested. Catalase, indole and $\mathrm{H}_{2} \mathrm{~S}$ are not produced and nitrate is not reduced. Acetate and lactate are produced as end products of metabolism. The Rapid ID32A profile is 4516053705 . The $\mathrm{G}+\mathrm{C}$ content of the DNA of the type strain is $64 \mathrm{~mol} \%$.

The type strain is D315A-29 ${ }^{\mathrm{T}}\left(=\mathrm{DSM} 13989^{\mathrm{T}}\right)$. The GenBank accession number for the 16S rRNA sequence is AF292374. Isolated from human subgingival plaque in adults with periodontitis.

\section{ACKNOWLEDGEMENTS}

This research was supported by grants DE-10374 and DE11443 from the National Institute of Dental and Craniofacial Research and by grant 058950 from the Wellcome Trust and a grant from Guy's Hospital Special Trustees. We thank W.E.C. and L.V.H. Moore for giving a large selection of their collection to Dr Anne Tanner. We thank Dr Tanner for transporting the collection from Virginia to Massachusetts and providing us with some of the Moores' strains.

\section{REFERENCES}

Anderson, R. C., Rasmussen, M. A., Jensen, N. S. \& Allison, M. J. (2000). Denitrobacterium detoxificans gen. nov., sp. nov., a ruminal bacterium that respires on nitrocompounds. Int J Syst Evol Microbiol 50, 633-638.

Collins, M. D. \& Wallbanks, S. (1992). Comparative sequence analyses of the 16S rRNA genes of Lactobacillus minutus,
Lactobacillus rimae and Streptococcus parvulus: proposal for the creation of a new genus Atopobium. FEMS Microbiol Lett 74, 235-240.

Collins, M. D., Fernandez, F. \& Howarth, O. W. (1985). Isolation and characterization of a novel vitamin-K from Eubacterium lentum. Biochem Biophys Res Commun 133, 322-328.

Dewhirst, F. E., Tamer, M. A., Ericson, R. E., Lau, C. N., Levanos, V. A., Boches, S. K., Galvin, J. L. \& Paster, B. J. (2000). The diversity of periodontal spirochetes by $16 \mathrm{~S}$ rRNA analysis. Oral Microbiol Immunol 15, 196-202.

Felsenstein, J. (1993). PHYLIP (Phylogeny Inference Package) version 3.5c. Distributed by the author. Department of Genetics: University of Washington, Seattle, WA, USA.

Haas, F. \& König, H. (1988). Coriobacterium glomerans gen. nov., sp. nov. from the intestinal tract of the red soldier bug. Int J Syst Bacteriol 38, 382-384.

Holdeman, L. V. H., Cato, E. P. \& Moore, W. E. C. (1977). Anaerobe Laboratory Manual, 4th edn. Blacksburg, VA: Virginia Polytechnic Institute and State University.

Jukes, T. H. \& Cantor, C. R. (1969). Evolution of protein molecules. In Mammalian Protein Metabolism, pp. 21-132. Edited by H. N. Munro. New York: Academic Press.

Kageyama, A., Benno, Y. \& Nakase, T. (1999a). Phylogenetic and phenotypic evidence for the transfer of Eubacterium aerofaciens to the genus Collinsella as Collinsella aerofaciens gen. nov., comb. nov. Int J Syst Bacteriol 49, 557-565.

Kageyama, A., Benno, Y. \& Nakase, T. (1999b). Phylogenic and phenotypic evidence for the transfer of Eubacterium fossor to the genus Atopobium as Atopobium fossor comb. nov. Microbiol Immunol 43, 389-395.

Kusukawa, N., Uemori, T., Asada, K. \& Kato, I. (1990). Rapid and reliable protocol for direct sequencing of material amplified by the polymerase chain reaction. Biotechniques 9, 66-72.

Maidak, B. L., Cole, J. R., Lilburn, T. G. \& 9 other authors (2000). The RDP (Ribosomal Database Project) continues. Nucleic Acids Res 28, 173-174.

Mendes, E. N., Queiroz, D. M. M., Dewhirst, F. E., Paster, B. J., Moura, S. B. \& Fox, J. G. (1996). Helicobacter trogontum sp. nov., isolated from the rat intestine. Int J Syst Bacteriol 46, 916-921.

Moore, L. V. H., Bourne, D. M. \& Moore, W. E. C. (1994). Comparative distribution and taxonomic value of cellular fatty acids in thirty-three genera of anaerobic gram-negative bacilli. Int $J$ Syst Bacteriol 44, 338-347.

Nakazawa, F., Poco, S. E., Ikeda, T., Sato, M., Kalfas, S., Sundqvist, G. \& Hoshino, E. (1999). Cryptobacterium curtum gen. nov., sp. nov., a new genus of Gram-positive anaerobic rod isolated from human oral cavities. Int J Syst Bacteriol 49, 1193-1200, erratum 1952.

Olsen, I., Johnson, J. L., Moore, L. V. H. \& Moore, W. E. C. (1991). Lactobacillus uli sp. nov. and Lactobacillus rimae sp. nov. from the human gingival crevice and emended descriptions of Lactobacillus minutus and Streptococcus parvulus. Int J Syst Bacteriol 41, 261-266.

Paster, B. J. \& Dewhirst, F. E. (1988). Phylogeny of campylobacters, wolinellas, Bacteroides gracilis, and Bacteroides ureolyticus by $16 \mathrm{~S}$ ribosomal ribonucleic acid sequencing. Int $J$ Syst Bacteriol 38, 56-62.

Rodriguez Jovita, M., Collins, M. D., Sjödén, B. \& Falsen, E. (1999). Characterization of a novel Atopobium isolate from the human vagina: description of Atopobium vaginae sp. nov. Int J Syst Bacteriol 49, 1573-1576.

Saitou, N. \& Nei, M. (1987). The neighbor-joining method: a new 
method for reconstructing phylogenetic trees. Mol Biol Evol 4, 406-425.

Stackebrandt, E. \& Ludwig, W. (1994). The importance of using outgroup reference organisms in phylogenetic studies: the Atopobium case. Syst Appl Microbiol 17, 39-43.

Stackebrandt, E., Rainey, F. A. \& Ward-Rainey, N. L. (1997).

Proposal for a new hierarchic classification system, Actinobacteria classis nov. Int J Syst Bacteriol 47, 479-491.

Summanen, P., Baron, E. J., Citron, D. M., Strong, C. A., Wexler,
H. M. \& Finegold, S. M. (1993). Wadsworth Anaerobic Bacteriology Manual, 5th edn. Belmont, CA: Star Publishing.

Wade, W. G., Downes, J., Dymock, D., Hiom, S. J., Weightman, A. J., Dewhirst, F. E., Paster, B. J., Tzellas, N. \& Coleman, B. (1999). The family Coriobacteriaceae: reclassification of Eubacterium exiguum (Poco et al. 1996) and Peptostreptococcus heliotrinreducens (Lanigan 1976) as Slackia exigua gen. nov., comb. nov. and Slackia heliotrinireducens comb. nov., and Eubacterium lentum (Prevot 1938) as Eggerthella lenta gen. nov., comb. nov. Int J Syst Bacteriol 49, 595-600. 